\title{
IGF-1 receptor signalling determines the mitogenic potency of insulin analogues in human smooth muscle cells and fibroblasts
}

\author{
K. Eckardt • C. May • M. Koenen • J. Eckel
}

Received: 21 June 2007 / Accepted: 11 July 2007 / Published online: 18 September 2007

(C) Springer-Verlag 2007

\begin{abstract}
Aims/hypothesis Mitogenic activity of insulin and insulin analogues and the involvement of the IGF-1 receptor (IGF$1 \mathrm{R})$ is still a controversial issue. We compared levels of the proteins IGF-1R and insulin receptor (InsR) in fibroblasts and smooth muscle cells from healthy donors and assessed the downstream signalling and growth-promoting activity of insulin and insulin analogues.

Methods DNA synthesis was monitored in human fibroblasts and coronary artery smooth muscle cells. Using small interfering RNAs, the levels of IGF-1 and InsR were reduced by 95 and $75 \%$, respectively.

Results Enhanced mitogenic potency of insulin and insulin analogues was observed which correlated with increased levels of IGF-1R and/or IRS-1. A reduction in the IGF-1R level significantly blunted stimulation of Akt phosphorylation by IGF-1, AspB10 and glargine by 72,58 and $40 \%$, respectively. Akt phosphorylation in response to insulin remained unaffected. Silencing of InsR did not significantly alter Akt phosphorylation in response to IGF-1, AspB10 and glargine. IGF-1R knockdown reduced the stimulation of DNA synthesis in response to IGF-1 and glargine to a level identical to that produced by insulin.

Conclusions/interpretation These data show a prominent role of IGF-1R/Akt signalling in mediating the mitogenic effects
\end{abstract}

K. Eckardt $\cdot$ C. May $\cdot$ M. Koenen · J. Eckel $(\bowtie)$

Institute of Clinical Biochemistry and Pathobiochemistry,

German Diabetes Center,

Auf'm Hennekamp 65,

D-40225 Dusseldorf, Germany

e-mail: eckel@uni-duesseldorf.de

URL: www.ddz.uni-duesseldorf.de of insulin analogues. Regular insulin stimulates DNA synthesis by exclusively activating InsR, whereas insulin analogues mainly signal through IGF-1R. It is suggested that inter-individual differences in the levels of proteins of the IGF-1R system may function as a critical determinant of the mitogenic potency of insulin analogues.

Keywords IGF-1 receptor - Insulin analogues ·

Insulin receptor $\cdot$ Mitogenic potential $\cdot$ Smooth muscle cells

$\begin{array}{ll}\text { Abbreviations } \\ \text { ECL } & \text { enhanced chemiluminescence } \\ \text { ERK1/2 } & \text { extracellular regulated kinase } 1 / 2 \\ \text { Fib } & \text { human dermal fibroblasts } \\ \text { HRP } & \text { horseradish peroxidase } \\ \text { IGF-1R } & \text { IGF-1 receptor } \\ \text { IGF-1R } \beta & \text { IGF-1 receptor } \beta \text { subunit } \\ \text { InsR } & \text { insulin receptor } \\ \text { InsR } \beta & \text { insulin receptor } \beta \text { subunit } \\ \text { SiRNA } & \text { small interfering RNA } \\ \text { SkM } & \text { human skeletal muscle cells } \\ \text { SMC } & \text { human coronary artery smooth muscle cell } \\ \text { TBS } & \text { Tris-buffered saline }\end{array}$

\section{Introduction}

A variety of studies have documented significant improvements in the therapy of type 1 and 2 diabetes due to the introduction of different insulin analogues into clinical use [1-7]. Advantages of short-acting artificial insulin molecules compared with conventional insulin preparations are 
better blood glucose control, faster onset of action and the short duration time [8]. These effects have been described for patients with type 1 and type 2 diabetes [9, 10]. The long-acting insulin analogue glargine forms depots at the injection site by precipitation and is therefore slowly absorbed into the systemic circulation. In clinical studies it has been shown that treatment with glargine leads to less nocturnal hypoglycaemia, comparable or improved efficiency and minimal variability between patients compared with conventional insulin preparations $[11,12]$.

Despite these advantages, some questions concerning the safety of insulin analogues remain open. It is known that modifications of the insulin molecule in the B10 and B26-B30 region are able to alter the affinity towards the IGF-1 receptor (IGF-1R) [13]. This has been demonstrated for AspB10, which is known for its strong tumourigenic action [14]. Generally, the mitogenic potential of a certain insulin analogue may result from (1) an enhanced affinity towards IGF-1R [13]; (2) the time of occupancy of the insulin receptor (InsR) by this analogue $[15,16]$; and (3) a combination of IGF-1- and InsR-mediated processes.

Because of the high degree of similarity, insulin/IGF-1 hybrid receptors can form by heterodimerisation [17]. The abundance of these hybrid receptors has been shown in a range of mammalian tissues [18-20]. There are controversial debates ongoing concerning the question whether InsR, IGF-1R and/or hybrid receptors play a role in mediating the biological effects of insulin analogues. Kurtzhals et al. [21] used the osteosarcoma cell line Saos/B10 to determine the mitogenic potency of insulin analogues and reported glargine to be eightfold more potent than human insulin in stimulating DNA synthesis. On the other hand, Berti et al. [22] analysed the mitogenic effect of glargine in rat fibroblasts overexpressing the human InsR and could not find differences between human insulin and glargine. Most of these studies were done in tumour cell lines or in cell systems overexpressing the human InsR and thus do not represent the normal status of primary human cells. Recently, Staiger et al. [23] reported that glargine and human insulin are not different in their proliferative effects on human coronary artery endothelial and smooth muscle cells.

In the present investigation we have tested the proliferative effects of insulin, AspB10, glulisine, lispro, aspart and glargine by measuring DNA synthesis in human dermal fibroblasts (Fib) and coronary artery smooth muscle cells (SMC) from different donors. We observed a mitogenic potency for insulin and the tested insulin analogues that correlated with high levels of proteins of the IGF-1R system. In vitro knockdown of IGF-1R reduced the augmented growth-promoting activity of glargine and IGF-1 to the level of that of insulin. It is suggested that the levels of IGF-1R system proteins may define an individual susceptibility towards the growth-promoting effects of insulin analogues.

\section{Materials and methods}

Materials Fib, SMC, skeletal muscle cells (SkM) and the appropriate cell culture media were purchased from Promocell (Heidelberg, Germany). FCS was supplied by Gibco (Invitrogen, Carlsbad, CA, USA). The Cell Proliferation ELISA (BrdU, chemiluminescent) and protease inhibitor cocktail tablets were from Roche (Mannheim, Germany). Human IGF-1 was obtained from Biomol (Hamburg, Germany). Regular human insulin and the insulin analogues AspB10, glulisine, lispro, aspart and glargine were products of Sanofi-Aventis (Frankfurt, Germany). Reagents for SDSPAGE were supplied by Amersham Pharmacia Biotech (Braunschweig, Germany) and by Sigma (Munich, Germany). The following antibodies were used: anti-IGF-1R $\beta$ subunit (IGF-1R $\beta$; C-20; Santa Cruz Biotechnology, Santa Cruz, CA, USA); anti-InsR $\beta$ subunit (anti-InsR $\beta$ ), anti- $\alpha$-tubulin and anti-actin (Calbiochem/Merck, Darmstadt, Germany); anti-IRS-1 (Upstate/Millipore, Billerica, MA, USA); antiAkt, anti-phospho-Akt (Ser473) and anti-extracellular regulated kinase (ERK)1/2 (Cell Signaling Technology, Danvers, MA, USA); and horseradish peroxidase (HRP)-conjugated anti-rabbit and anti-mouse IgG (Promega, Mannheim, Germany). Greiner Bio-one (Frickenhausen, Germany) supplied the Leucosep tubes; the Biocoll solution (density $1.077 \mathrm{~g} / \mathrm{ml}$ ) was from Biochrom (Berlin, Germany). HiPerFect transfection reagent and non-silencing control small interfering RNA (siRNA) were obtained from Qiagen (Hilden, Germany), Silencer-validated siRNA specific for human IGF-1R and human InsR were products of Ambion (Austin, TX, USA). All other chemicals were of the highest analytical grade commercially available and were purchased from Sigma.

Cell culture Primary Fib of two healthy donors (white, female, 52 and 32 years [F52, F32]) and primary SMC of four healthy donors (white, male, 40 and 21 years [M40, M21]; female, 56 and 16 years [F56, F16]) were supplied as proliferating cells $\left(5 \times 10^{5}\right.$ cells $)$ and kept in culture according to the manufacturer's protocol. For the experiments, confluent cells between passage number 5 and 7 were used. SkM of one donor (male, 9 years) were differentiated to myotubes according to the manufacturer's protocol. Lysates were prepared as described below on day 6 of differentiation and used as the reference for comparing the various protein levels of different cell types and donors. MCF-7 and MDA-MB-231 human mammary tumour cells were purchased from the American Type Culture Collection (Manassas, VA, USA) and cultured as detailed by the manufacturer.

In vitro analysis of growth-promoting activity To monitor DNA synthesis, Fib or SMC were seeded in 96 well plates and allowed to attach for $24 \mathrm{~h}$, followed by serum starvation for $30 \mathrm{~h}$ (Fib) or $24 \mathrm{~h}$ (SMC). Cells were then stimulated for 
$16 \mathrm{~h}$ with the different peptide hormones with the simultaneous addition of BrdU. For the analysis of cell proliferation we used the chemiluminescent BrdU ELISA kit from Roche according to the manufacturer's protocol. The signals were visualised and evaluated on a LumiImager work station using image analysis software (Boehringer, Mannheim, Germany).

Immunoblotting For analysis of the levels of the proteins InsR, IGF-1R, IRS-1, Akt and ERK1/2 in SMC and Fib, cells were seeded in Petri dishes and grown to confluence. Lysates were prepared with ice-cold lysis buffer containing $50 \mathrm{mmol} / \mathrm{l} \mathrm{HEPES}$ (pH 7.4), 1\% Triton X-100 (vol./vol.), $1 \mathrm{mmol} / 1 \mathrm{Na}_{3} \mathrm{VO}_{4}$ and protein inhibitor cocktail. After incubation for $2 \mathrm{~h}$ at $4{ }^{\circ} \mathrm{C}$ the suspension was centrifuged at $10,000 \mathrm{~g}$ for $20 \mathrm{~min}$. Ten or 20 micrograms of protein were loaded per sample, separated by SDS-PAGE using horizontal gels and transferred to polyvinylidene fluoride membranes. The membranes were blocked in Tris-buffered saline (TBS) containing 0.1\% Tween-20 (vol./vol.) and 5\% (wt/vol.) non-fat dry milk or $5 \%$ (wt/vol.) BSA and then incubated overnight with the appropriate antibodies. After repeated washing, the membranes were incubated with HRPconjugated secondary antibody for $1 \mathrm{~h}$ at room temperature. The Immobilon HRP substrate from Millipore (Billerica, MA, USA) was used for enhanced chemiluminescence (ECL) detection. The signals were visualised and evaluated on a Lumilmager work station.

Isolation of peripheral mononuclear cells Fresh human whole-blood samples were collected from 16 healthy donors and diluted 1:2 with balanced salt solution. The separation of lymphocytes and peripheral mononuclear cells based on density gradient centrifugation was performed with Leucosep tubes (Greiner Bio-one) according to the manufacturer's protocol. After centrifugation, the cell suspension was washed with $3 \times 10 \mathrm{ml}$ PBS and centrifuged for $10 \mathrm{~min}$ at $600 \mathrm{~g}$. The resulting pellet was resuspended in $1 \mathrm{ml}$ PBS, the cells were then plated on six well plates and incubated at $37^{\circ} \mathrm{C}$ for $4 \mathrm{~h}$ to allow the monocytes to attach. After this, cells were washed with $4 \times 1 \mathrm{ml}$ PBS to remove the lymphocytes and lysed with ice-cold lysis buffer as described above. Twenty micrograms of protein per sample were processed by SDS-PAGE and western blotting. The membrane was incubated with anti-IGF-1R $\beta$ overnight and processed as described above. After detection of the signal the membrane was stripped and re-incubated with anti-actin to confirm equal loading.

Silencing of IGF-1R and InsR in Fib Fib of donor F52 were seeded in six well plates and washed with fibroblast basal medium containing 1\% (vol./vol.) FCS after $24 \mathrm{~h}$. The siRNA was used at $20 \mathrm{nmol} / \mathrm{l}$ for IGF-1R and $10 \mathrm{nmol} / \mathrm{l}$ for
InsR with HiPerFect as transfection reagent according to the manufacturer's protocol. The applied siRNA was either non-silencing RNA as negative control or siRNA specifically silencing IGF-1R (IGF-1R siRNA) or InsR (InsR siRNA). Lysates for immunoblotting were prepared $72 \mathrm{~h}$ after transfection and the levels of IGF-1R, InsR, Akt and ERK1/2 were analysed.

After silencing IGF-1R or InsR, stimulation experiments were performed to analyse possible changes of downstream signalling pathways. Forty-eight hours after transfection with the appropriate siRNA, the medium was changed to fibroblast basal medium for $24 \mathrm{~h}$ starvation. Cells were then stimulated with regular insulin $(100 \mathrm{nmol} / \mathrm{l})$, IGF-1 $(10 \mathrm{nmol} / \mathrm{l}), \operatorname{AspB} 10(100 \mathrm{nmol} / \mathrm{l})$ and glargine $(100 \mathrm{nmol} / \mathrm{l})$ for 15 min. Cells were washed once with ice-cold PBS and scratched into ice-cold lysis buffer containing $50 \mathrm{mmol} / \mathrm{l}$ Tris-HCl (pH 7.4), 1\% NP-40 (vol./vol.), $0.25 \%$ sodium deoxycholate (wt/vol.), $150 \mathrm{mmol} / 1 \mathrm{NaCl}, 1 \mathrm{mmol} / \mathrm{l} \mathrm{EGTA}$, $1 \mathrm{mmol} / 1 \mathrm{Na}_{3} \mathrm{VO}_{4}, 1 \mathrm{mmol} / 1 \mathrm{NaF}$ and protein inhibitor cocktail. After incubation for $2 \mathrm{~h}$ at $4^{\circ} \mathrm{C}$ the suspension was centrifuged at $10,000 \mathrm{~g}$ for $20 \mathrm{~min}$. Immunoblotting was performed as outlined above. The membranes were blocked with TBS containing $0.1 \%$ Tween-20 (vol./vol.) and 5\% BSA (wt/vol.). Incubation with anti-phospho-Akt was overnight, incubation with the secondary antibody for $1 \mathrm{~h}$. After detection, membranes were incubated with anti- $\alpha$-tubulin for normalisation.

To analyse the effect of IGF-1R silencing on growthpromoting activity, cells were seeded on 96 well plates and allowed to attach for $24 \mathrm{~h}$. Transfection with non-silencing RNA and IGF-1R siRNA was performed as described above. After $24 \mathrm{~h}$, the medium was changed to fibroblast basal medium to starve the cells for $30 \mathrm{~h}$. Cells were then stimulated for $16 \mathrm{~h}$ with either regular insulin, IGF-1 or glargine $(10 \mathrm{nmol} / \mathrm{l})$, in the presence of $\mathrm{BrdU}$, as detailed above. All experiments were performed in quadruplicate. Cells were then processed for LumiImager analysis, as outlined before.

Presentation of data and statistics Statistical analysis was carried out by ANOVA. All statistical analyses were done using StatView software (SAS Institute, Cary, NC, USA). A $p$ value of less than 0.05 was considered to be statistically significant. Significance levels are indicated in the figures. Data are shown as means \pm SEM.

\section{Results}

Protein level analysis of the IGF-1R pathway in primary cells of different donors To establish a cell culture model of primary human cells with a defined abundance of IGF-1R 


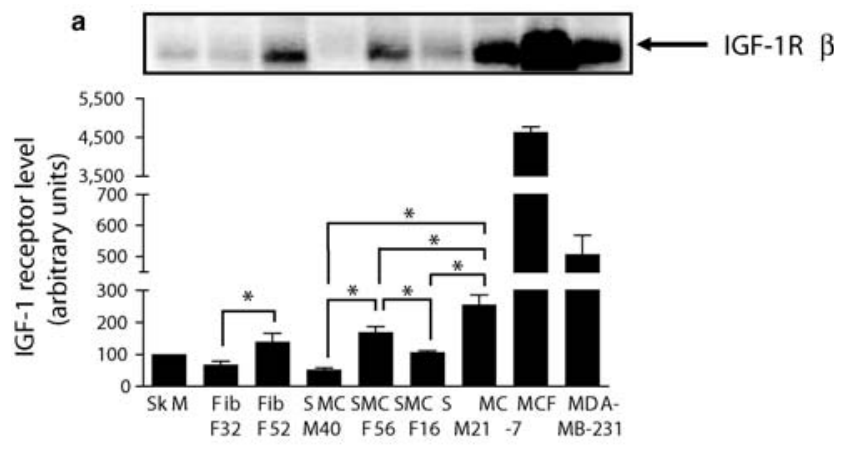

b
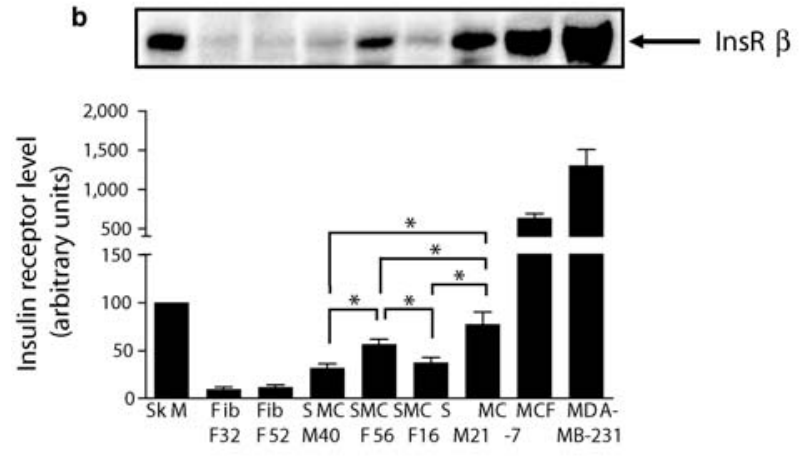

c
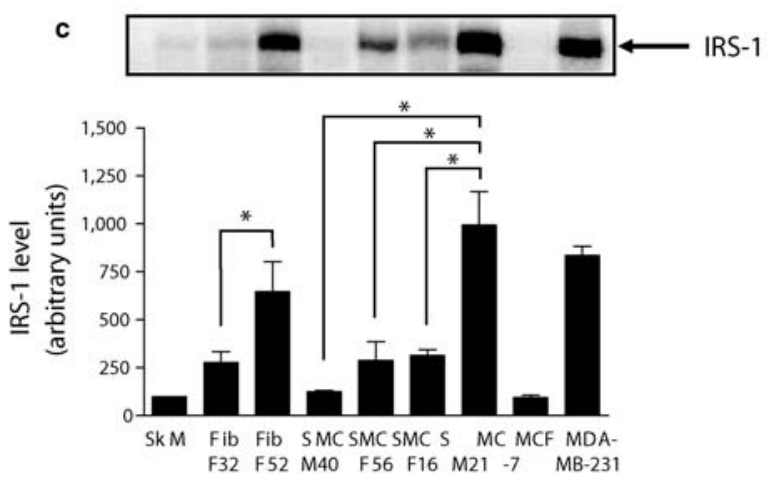

Fig. 1 IGF-1R (a), InsR (b) and IRS-1 (c) levels in different cell types and donors. Whole-cell lysates were resolved by SDS-PAGE, blotted and immunodetected with antibodies against IGF-1R $\beta$, InsR $\beta$ or IRS-1 using the ECL system. Representative blots are shown. Quantification was performed on a LumiImager work station. The protein level of differentiated SkM was used as the reference and set to $100 \%$. The data are presented as means \pm SEM, $n \geq 3 .{ }^{*} p<0.05$ for difference in protein levels between donors of the same cell type

and its downstream signalling components, we analysed levels of IGF-1R, InsR, IRS-1, Akt and ERK1/2 in Fib and SMC of different healthy donors. For comparison, SkM and the human breast tumour cell lines MCF-7 and MDA-MB-231 were included.

As shown in Fig. 1, Fib and SMC have remarkably lower levels of IGF-1R and InsR than the tumour cells. For IGF-1R, both cell types are more or less comparable to SkM, but we found obvious differences between the donors. For SMC, two donors (F56, M21) showed a three- to fourfold higher level of IGF-1R compared with donor M40 and a two- to threefold higher level compared with donor F16
(Fig. 1a). For Fib donor F52 we found a twofold higher level than for F32. Furthermore, InsR was upregulated in SMC donor F56 and M21 (Fig. 1b) with M21 having the most abundant InsR level among the SMC donors. The Fib donors express much less InsR than do SkM or SMC and do not show differences in levels of the protein.

These individual differences were also observed further downstream at the level of IRS-1 (Fig. 1c). Again, donors of Fib and SMC show marked differences among themselves (Fib F32: 278 $\pm 96 \%$ and F52: 648 $\pm 218 \%$; SMC M40: $126 \pm 11 \%$, F56: $289 \pm 170 \%$, F16: $314 \pm 55 \%$ and M21: $995 \pm 247 \%)$. The differences reached statistical significance between the Fib donors and between SMC donor M21 and the other SMC donors. For Akt, the Fib donors were significantly different from each other, as also observed for some SMC donors (Fig. 2, upper panel). However, these differences were less prominent compared with IGF-1R and IRS-1 (see Fig. 1). For ERK1/2, no significant differences between the different Fib and SMC donors could be detected (Fig. 2). In subsequent experiments (see Figs 6, 7 and 8), Fib F52 was used as a model of potential augmented activity of the IGF-1 signalling pathway.

Additionally, we isolated human monocytes from wholeblood samples to analyse the variation in the IGF-1R level in a larger group of 16 donors. As shown in Fig. 3, we observed a substantial natural variation in the IGF-1R level. Four donors exhibited very prominent IGF-1R levels compared with the other donors, whereas in some other donors IGF-1R was even undetectable. There was no obvious correlation between sex, age and the IGF-1R level. These data are consistent with our findings in Fib and SMC and support the notion that IGF-1R may be subject to a substantial individual variation.

Growth-promoting activity of insulin analogues in SMC and Fib To assess if the differences in levels of IGF-1R system proteins may be critical for the proliferative activity of insulin and insulin analogues, we monitored DNA synthesis in SMC and Fib using the incorporation of BrdU and a highly sensitive chemiluminescence immunoassay. As presented in Fig. 4a, for SMC donor F56 (high level of IGF-1R) all insulin analogues and insulin itself induced a significant stimulation of DNA synthesis, at least at $100 \mathrm{nmol} / \mathrm{l}$. At this concentration, the growth-promoting activity of glargine was comparable to AspB10 and significantly higher than regular insulin. Similar results were found for M21, with glargine being slightly more potent than AspB10 and reaching significance compared with regular insulin at $100 \mathrm{nmol} / \mathrm{l}$ (Fig. 4b). Also, the absolute level of insulin-stimulated DNA synthesis at $100 \mathrm{nmol} / \mathrm{l}$ compared with basal was higher than in any other donor (183 vs 138\% (F56), 145\% (M40) and 123\% (F16), Fig. 4a-d), most likely due to the high level of InsR (see 
a
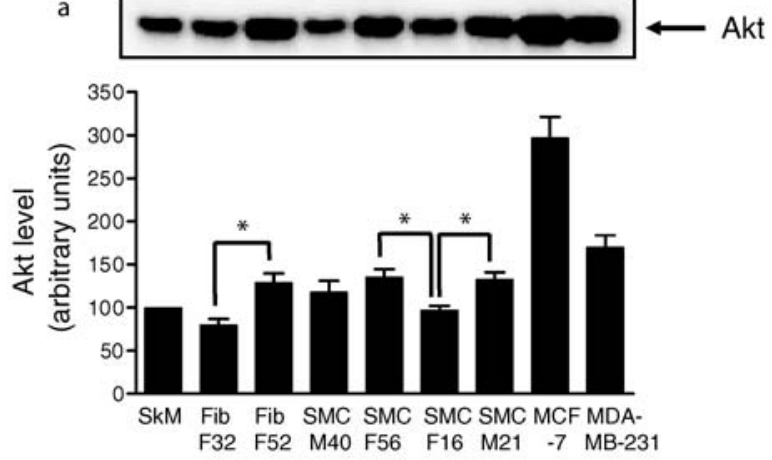

b
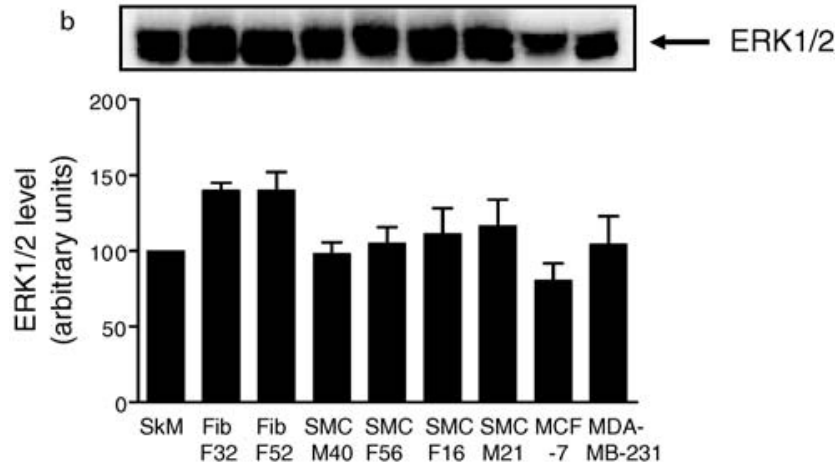

Fig. 2 Akt (a) and ERK1/2 (b) levels in different cell types and donors. Cell lysates were immunoblotted for Akt and ERK1/2 and quantification was performed as outlined in Fig. 1. The data are presented as means \pm SEM, $n \geq 3$. ${ }^{*} p<0.05$ for difference in protein levels between donors of the same cell type

Fig. 1). Donor F16 showed significant stimulation of DNA synthesis after treatment with $100 \mathrm{nmol} / 1$ insulin and all insulin analogues except aspart (Fig. 4c). For SMC M40 (Fig. 4d) neither insulin nor the insulin analogues glulisine and glargine were able to produce a significant stimulation of DNA synthesis, while for AspB10, lispro and aspart this was observed. Furthermore, in M40 and F16 (low level of IGF-1R ) none of the tested analogues was significantly different from insulin. We therefore conclude that IGF-1R is of critical importance for the mitogenic activity of insulin analogues.

Additional evidence for this notion was obtained by measuring the dose-dependent stimulation of DNA synthesis after incubation with regular insulin, AspB10 and glargine in the Fib donors F52 and F32. In F52 (high level of IGF-1R and IRS-1) glargine was significantly more mitogenic than regular insulin at concentrations between 5 and $100 \mathrm{nmol} / \mathrm{l}$ but was not different from insulin in F32 (Fig. 5) at high concentrations of the peptide.

Silencing of $I G F-1 R$ and InsR and functional implications for the growth-promoting activity of insulin analogues To directly investigate the role of IGF-1R vs InsR in the augmented proliferative effect of insulin analogues, we established the in vitro knockdown of IGF-1R and InsR in Fib of donor F52. Figure 6 shows the quantification of IGF-1R, InsR, Akt and ERK1/2 levels $72 \mathrm{~h}$ after transfection. The protein level of the non-silencing RNA control was set to $100 \%$. For IGF-1R we observed a downregulation of the level of this protein to $4 \%$ of the control level after $72 \mathrm{~h}$ (Fig. 6a), while no significant changes in InsR, Akt or ERK1/2 protein levels (Fig. 6) were observed. However, the knockdown of InsR to $25 \%$ of control levels (Fig. 6b) raised IGF-1R level to $125 \%$ of the non-silencing RNA control, while Akt and ERK1/2 levels remained unchanged.

We then tested the influence of IGF-1R and InsR silencing on signal transduction after acute stimulation with regular insulin, IGF-1, AspB10 and glargine (Fig. 7). The resulting phospho-signal after $15 \mathrm{~min}$ insulin incubation in 'no transfection' was set to $100 \%$ and all other signals were referred to it. Akt phosphorylation in response to IGF-1, AspB10 and glargine was significantly higher compared with insulin (Fig. 7a). After silencing IGF-1R, the stimulation of Akt phosphorylation by IGF-1, AspB10 and glargine was significantly reduced by 72,58 and $40 \%$, respectively. No changes of Akt activation were observed for insulin treatment (Fig. 7c). Reduction of the InsR level to $25 \%$ reduced the phosphorylation of Akt after acute insulin stimulation by $40 \%$ (Fig. 7d), while stimulation with IGF-1, AspB10 and glargine produced an unaltered response under these conditions.

Stimulation of DNA synthesis by regular insulin, IGF-1 and glargine in IGF-1R-silenced Fib is presented in Fig. 8. As an additional positive control we used fibroblast basal medium supplemented with 5\% FCS. Basal BrdU incorporation was set to $100 \%$ and used as reference. In the control situations, incubation of Fib with 5\% FCS, IGF-1 and glargine resulted in a three- to fourfold enhanced growth-

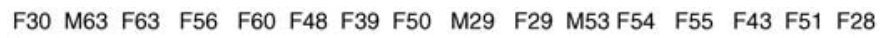

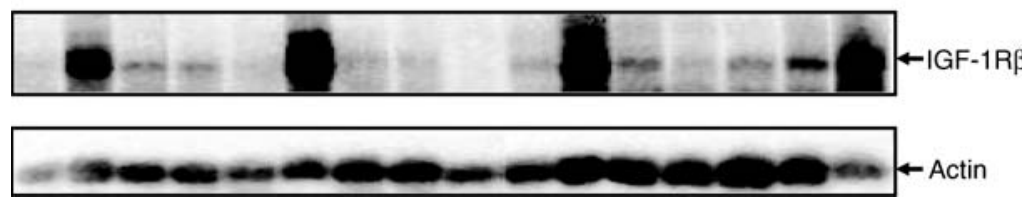

Fig. 3 IGF-1R level in human monocytes. The cells were isolated from fresh whole-blood samples of 16 randomly chosen healthy donors. Cell lysates were resolved by SDS-PAGE, blotted and immunodetected with antibodies against IGF-1R $\beta$ and actin using the ECL system. The labels above the lanes indicate the sex $(M$ male, $F$ female) and age of the donors 
promoting activity compared with regular insulin. Silencing of IGF-1R reduced the stimulation of DNA synthesis in response to IGF-1 and glargine by $60-80 \%$, a level comparable to that produced by insulin. The BrdU incorporation in response to $5 \% \mathrm{FCS}$ and insulin itself remained unaffected.

\section{Discussion}

Proliferation and migration of smooth muscle cells in response to growth factors represents a key step in the initiation of atherosclerosis [24] and it has been shown that IGF-1 may exert a prominent stimulatory action on this process $[25,26]$. Some insulin analogues were reported to exhibit a markedly increased IGF-1R affinity and mitogenic potency, which may represent a still undefined safety risk [20] regarding atherogenesis. In the present study we have used primary human cells with a broad range of levels of IGF-1 signalling system proteins. Our data identify IGF-1R as the key mediator of the augmented growth-promoting activity of insulin analogues in SMC and Fib.
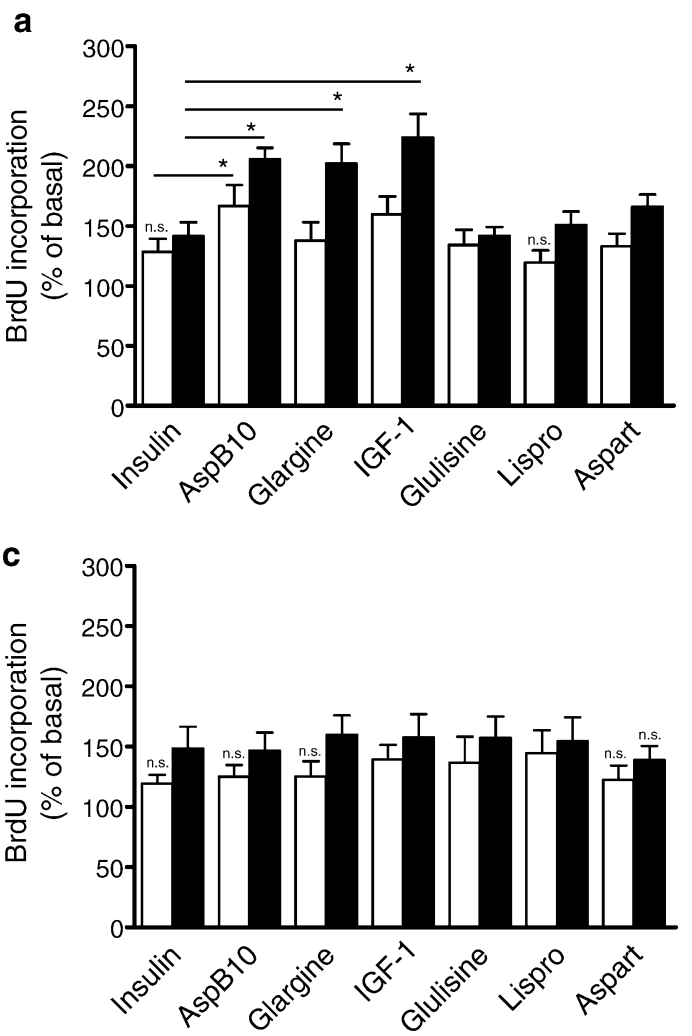

Fig. 4 Effect of regular insulin, AspB10, glargine, IGF-1, glulisine, lispro and aspart on the incorporation of BrdU into DNA in SMC from donor F56 (a), donor M21 (b), donor F16 (c) and donor M40 (d). Cells were serum starved for $24 \mathrm{~h}$ and subsequently incubated with BrdU in the absence or presence of peptide hormones for $16 \mathrm{~h}$ (open bars, $10 \mathrm{nmol} / \mathrm{l}$; closed bars, $100 \mathrm{nmol} / \mathrm{l}$. For IGF-1: open bars, $2 \mathrm{nmol} / \mathrm{l}$;
A key finding of the present investigation is the observation that all tested insulin analogues and insulin itself can exhibit enhanced growth-promoting activity. Importantly, these results were strictly donor-specific and correlated with levels of the proteins IGF-1R, InsR and/or IRS-1. It has been shown that IRS-1 and InsR levels vary in different tissues of healthy human individuals [27, 28]. Furthermore, we found high variation in IGF-1R levels in monocytes isolated from a randomly chosen group of 16 healthy donors. In our study we found that Fib and SMC with higher IGF-1R, InsR and IRS-1 levels had an increased DNA synthesis when stimulated with insulin or any tested insulin analogue. The mitogenic potency of insulin itself is much more dependent on the InsR level, as observed in several donors and thoroughly supported by our IGF-1R knockout data (see Fig. 8). We therefore hypothesise that elevated levels of IGF-1R system proteins may function as a critical determinant of the mitogenic potency of insulin analogues. This would also imply an individual susceptibility to the mitogenic effects of insulin analogues. Clearly, our study is limited to four donors of

b

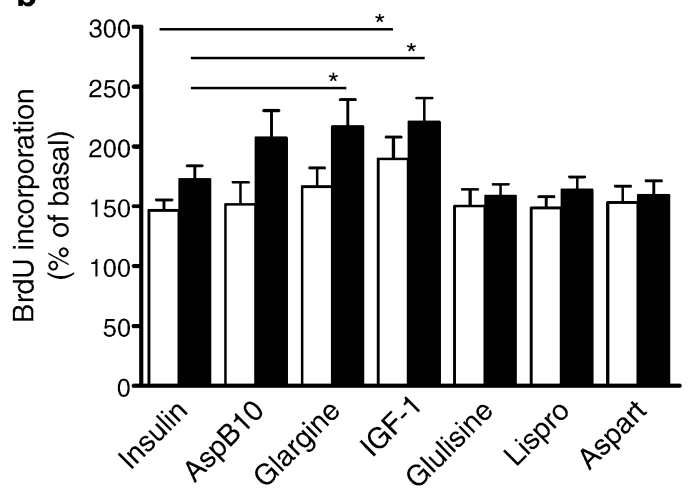

d

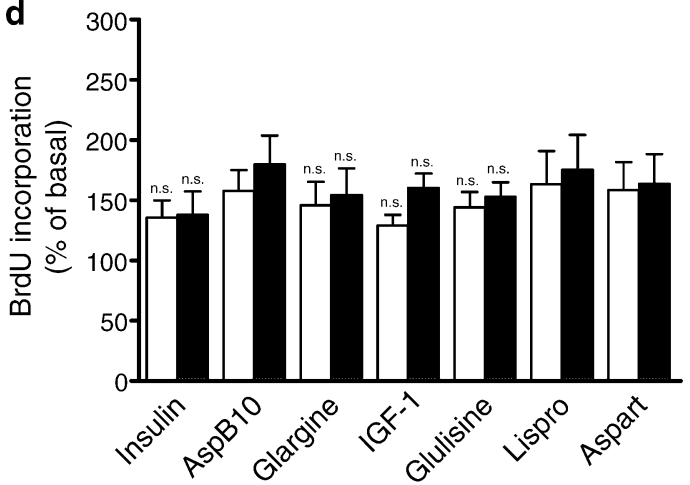

closed bars, $10 \mathrm{nmol} / \mathrm{l})$. Cells were fixed and denatured and the incorporation of BrdU was determined using an anti-BrdU antibody and ECL detection. Signals were quantified using Lumilmager software. Data are expressed relative to the basal control value, which was set as $100 \%$. The data are presented as means \pm SEM, $n \geq 7$. n.s. No significant stimulation over basal; ${ }^{*} p<0.05$ vs regular insulin 
a

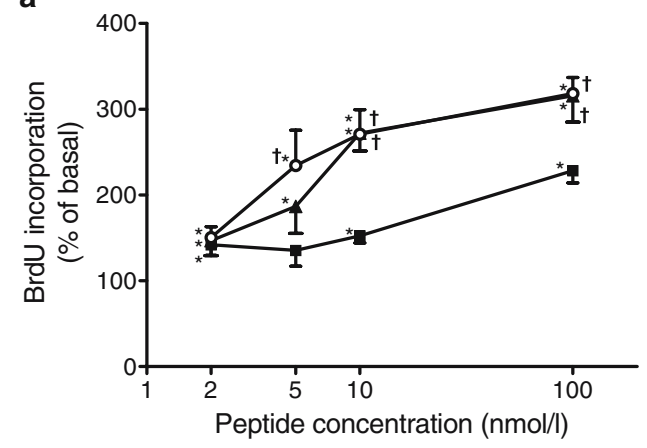

b

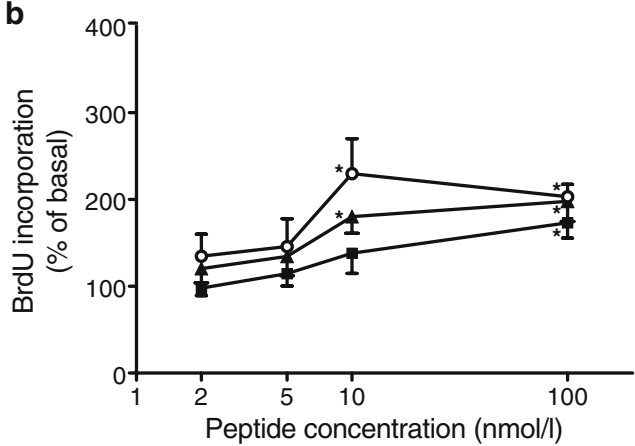

Fig. 5 Dose-response curve of BrdU incorporation into DNA in Fib of two different donors, F52 (a) and F32 (b), after stimulation with insulin (squares), AspB10 (triangles) or glargine (circles). Cells were serum starved for $30 \mathrm{~h}$ and stimulated with regular human insulin or the indicated insulin analogue. BrdU incorporation was determined as outlined in Fig. 3. The data are presented as means \pm SEM, $n \geq 5$, with peptide concentration on a logarithmic scale. ${ }^{*} p<0.05$ vs basal; $\dagger p<$ 0.05 vs regular insulin

SMC and two donors of Fib and it remains to be shown whether elevated levels of IGF-1R system proteins are relevant in a larger population. On the other hand, our data obtained in monocytes lend support to this notion. Our findings are in sharp contrast to a recent publication by Berti et al. [22], in which they studied the proliferative and anti-apoptotic effects of regular insulin and glargine in human coronary artery endothelial and smooth muscle cells. Both peptides were found to be unable to stimulate DNA synthesis even at concentrations up to $100 \mathrm{nmol} / \mathrm{l}$. It was concluded that neither insulin nor glargine may contribute to the development of atherosclerosis [22]. However, the levels of IGF-1R and IRS-1 were not determined and a detailed analysis of separate donors was not presented. Our results with SMC donor M40 and F16 (low level of IGF1R) are indeed consistent with the data of Staiger et al. [22]; however, completely different findings were obtained with SMC donors F56 and M21. These considerations support our notion that the individual IGF-1R level of is critical for the growth-promoting activity of insulin analogues and of insulin itself. We further conclude that a potential atherogenic potency of glargine cannot be ruled out.

The molecular basis of the enhanced mitogenic potency of insulin analogues has remained a controversial issue, with data favouring either the insulin or the IGF-1R signalling pathway [29]. Using in vitro knockdown of IGF-1R and InsR, we here provide direct evidence for a key role of the IGF-InsR/Akt signalling pathway in the augmented growthpromoting activity of insulin analogues. IGF-1, AspB10 and glargine produced a prominent activation of Akt and were significantly more potent than regular insulin. This is consistent with the well established role of Akt in the regulation of DNA synthesis, cell proliferation and cell survival [25-27]. Knockdown of IGF-1R by $>95 \%$ resulted in a substantially decreased Akt phosphorylation upon treatment with IGF-1,
Fig. 6 Protein expression after silencing of IGF-1R and InsR in Fib. Fib of donor F52 were transfected with 20 or $10 \mathrm{nmol} / \mathrm{l}$ siRNA as described in Methods. Lysates were prepared $72 \mathrm{~h}$ after transfection, immunoblotted and analysed for expression of IGF-1R (a), InsR (b), Akt (c) and ERK1/2 (d). All data were normalised to the level of $\alpha$-tubulin expression and are expressed relative to nonsilencing controls. Representative western blots are shown. The data are presented as means $\pm \mathrm{SEM}, n \geq$ 3. no transf. No transfection, neg. control transfection with non-silencing control RNA, si IGF-IR transfection with $20 \mathrm{nmol} / \mathrm{l} \mathrm{IGF-}$ 1R siRNA, si InsR transfection with $10 \mathrm{nmol} / \mathrm{l}$ InsR siRNA. ${ }^{*} p<0.05$ vs both controls
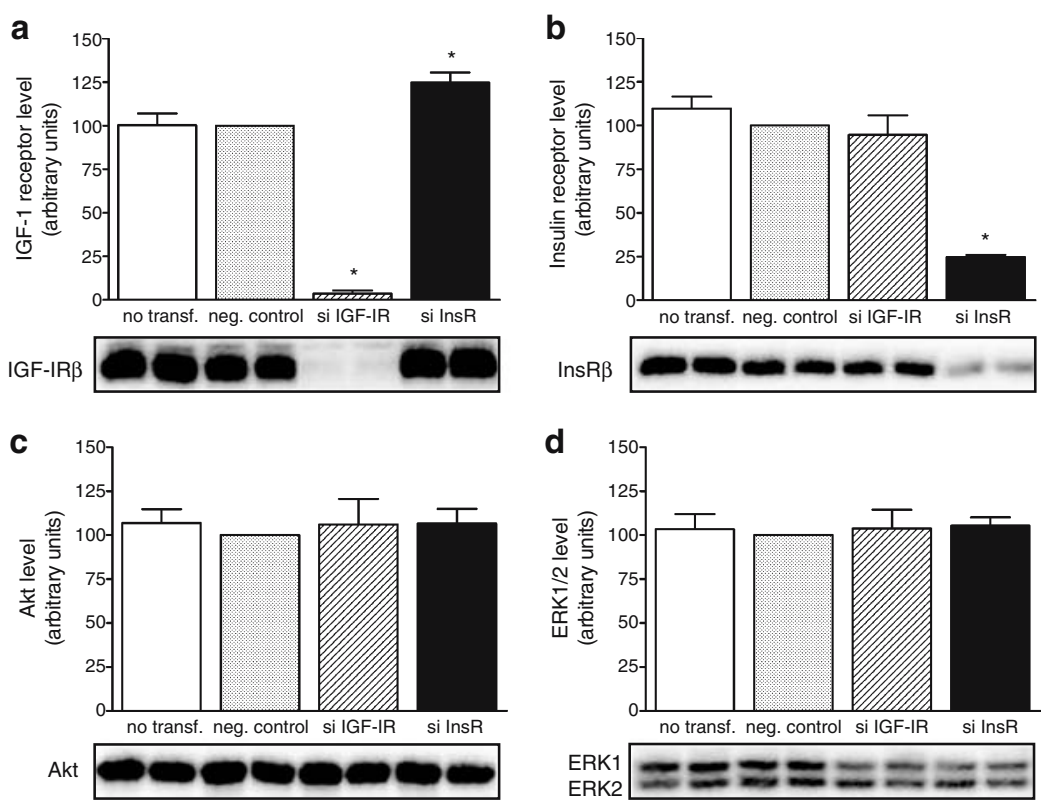

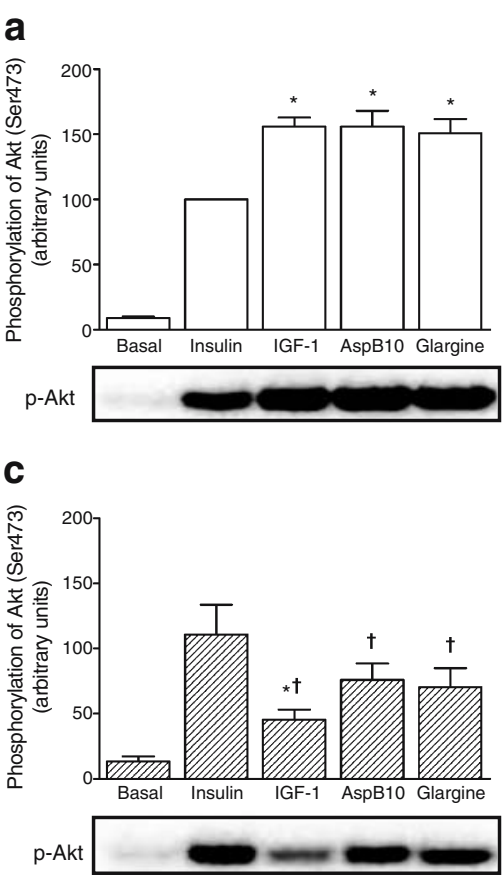

Fig. 7 Akt (Ser473) phosphorylation in IGF-1R- and InsR-silenced Fib after stimulation with insulin, IGF-1, AspB10 or glargine. After incubation in the absence or presence of siRNA for $72 \mathrm{~h}$, the cells were stimulated for $15 \mathrm{~min}$ with insulin, AspB10 or glargine at $100 \mathrm{nmol} / \mathrm{l}$ or with IGF-1 at $10 \mathrm{nmol} / \mathrm{l}$. Total cell lysates were resolved by SDSPAGE and immunoblotted with a phospho-specific Akt antibody. Blots were stripped and reprobed with anti- $\alpha$-tubulin to control for loading differences. Peptide-stimulated phosphorylation of Akt after no trans-

AspB10 and glargine. The remaining phosphorylation signal is probably due to signalling through InsR. Most importantly, silencing of IGF-1R significantly reduced the effect of IGF-1 and glargine on DNA synthesis to the level identical to that observed in response to insulin. The results obtained by knockdown of InsR further support our notion that the mitogenic activity of insulin analogues is mediated

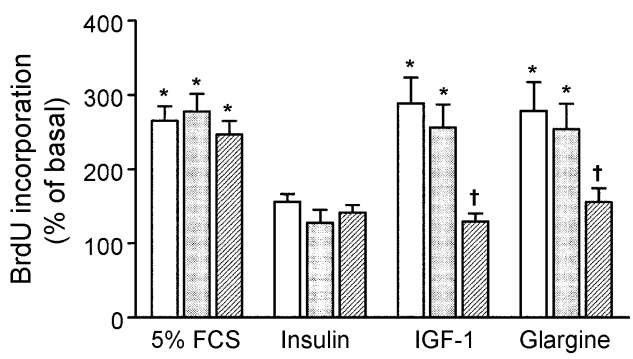

Fig. 8 BrdU incorporation into DNA in IGF-1R-silenced Fib after overnight stimulation with $5 \% \mathrm{FCS}$, insulin, IGF-1 or glargine at $10 \mathrm{nmol} / \mathrm{l}$. Basal incorporation was set to $100 \%$. Open bars represent no transfection, dotted bars represent non-silencing control RNA, hatched bars represent IGF-1R siRNA. Means \pm SEM, $n \geq 6$. *Significantly different $(p<0.05)$ from insulin-stimulated values, $\dagger p<0.05$ for downregulation of BrdU incorporation vs no transfection and nonsilencing control siRNA
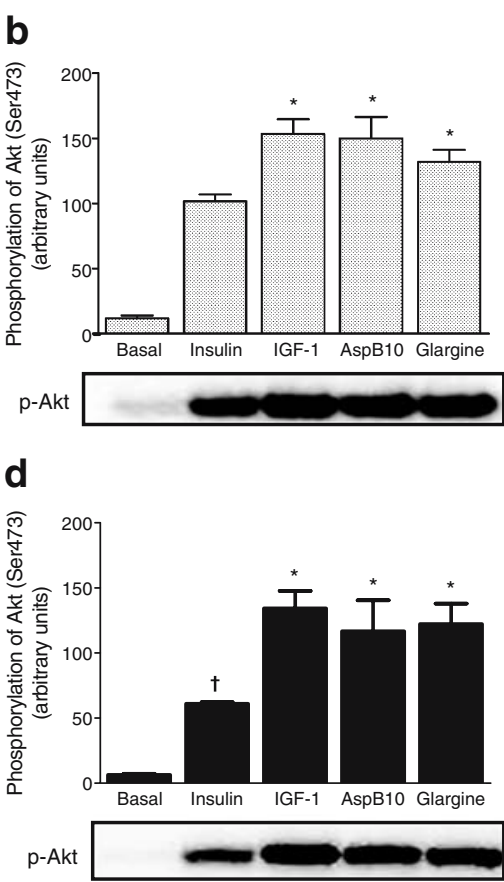

fection (a), incubation with non-silencing control RNA (b), incubation with IGF-1R siRNA (c) or incubation with InsR siRNA (d). Representative western blots are shown. All data were normalised to the level of $\alpha$-tubulin expression and are expressed relative to the insulin-stimulated control value (no transfection, a). The data are presented as means \pm SEM, $n \geq 3$. ${ }^{*} p<0.05$ vs insulin-stimulated control. $\dagger p<0.05$ vs corresponding values in both control situations. $p$-Akt Phosphorylated Akt

by IGF-1R. Despite reducing the InsR level by $75 \%$, the phosphorylation of Akt after acute stimulation with AspB10 and glargine remained at a high level, while the insulinstimulated phosphorylation was significantly reduced by $40 \%$. The remaining Akt phosphorylation signal is probably due to incomplete knockdown of InsR protein. To the best of our knowledge this is the first direct demonstration that the enhanced growth-promoting activity of glargine is mediated by IGF-1R in primary human cells.

Our results also indicate that regular insulin may have a higher specificity for its own receptor than AspB10, glargine and IGF-1. This is based on the observation that silencing of IGF-1R modified neither Akt activation nor DNA synthesis in response to insulin up to $100 \mathrm{nmol} / \mathrm{l}$, which would indicate that insulin acts exclusively through its own receptor under these conditions. This is consistent with the data of $\mathrm{Li}$ et al. [30], who reported that insulin at physiological concentrations selectively activates InsR and subsequently Akt, ERK1/2 and endothelial nitric oxide synthase. At high concentrations they found that IGF-1R $\beta$ is also phosphorylated; however, despite blocking the receptor with antibodies Akt phosphorylation in response to insulin remained unchanged. We suggest that insulin 
analogues act through both InsR and IGF-1R. Under these conditions the affinity of a certain insulin analogue towards IGF-1R becomes increasingly important. It has been shown that AspB10 and glargine have a six to eightfold and insulin lispro a 1.5 -fold higher affinity for IGF-1R than normal insulin [21], while aspart [31] and glulisine [32, 33] have a low affinity for IGF-1R, like normal insulin. Combining an insulin analogue with increased affinity for IGF-1R with an elevated level of IGF-1R may be a critical safety issue which needs to be further investigated.

In summary, we show here that regular insulin exhibits a growth-promoting activity on SMC depending on levels of insulin and proteins of the IGF-1 signalling pathway. The enhanced growth-promoting activity of insulin analogues is exclusively mediated by IGF-1R and further studies on a potential safety risk of these molecules are urgently required.

Acknowledgements This work was supported by the Ministerium für Wissenschaft und Forschung des Landes Nordrhein-Westfalen (Ministry of Science and Research of the State of North RhineWestphalia), the Bundesministerium für Gesundheit (Federal Ministry of Health), European Union COST Action B17 and the Lilly Foundation International. The secretarial assistance of B. Hurow is gratefully acknowledged.

Duality of interest The authors declare that there is no duality of interest associated with this manuscript.

\section{References}

1. Barnett AH (2003) A review of basal insulins. Diabet Med 20: 873-885

2. Bolli GB, Di Marchi RD, Park GD, Pramming S, Koivisto VA (1999) Insulin analogues and their potential in the management of diabetes mellitus. Diabetologia 42:1151-1167

3. Heller S (2002) Reducing hypoglycaemia with insulin analogues. Int J Obes Relat Metab Disord 26(Suppl 3):S31-S36

4. Hermansen K, Fontaine P, Kukolja KK, Peterkova V, Leth G, Gall MA (2004) Insulin analogues (insulin detemir and insulin aspart) versus traditional human insulins (NPH insulin and regular human insulin) in basal-bolus therapy for patients with type 1 diabetes. Diabetologia 47:622-629

5. Nattrass M (2004) Insulin therapy-realising the potential. Int J Obes Relat Metab Disord 28(Supp1 2):S1-S2

6. Stoneking K (2005) Initiating basal insulin therapy in patients with type 2 diabetes mellitus. Am J Health Syst Pharm 62:510-518

7. Vajo Z, Fawcett J, Duckworth WC (2001) Recombinant DNA technology in the treatment of diabetes: insulin analogs. Endocr Rev 22:706-717

8. Perriello G, Pampanelli S, Porcellati F et al (2005) Insulin aspart improves meal time glycaemic control in patients with type 2 diabetes: a randomized, stratified, double-blind and cross-over trial. Diabet Med 22:606-611

9. Rosenfalck AM, Thorsby P, Kjems L et al (2000) Improved postprandial glycaemic control with insulin Aspart in type 2 diabetic patients treated with insulin. Acta Diabetol 37:41-46
10. Brunner GA, Hirschberger S, Sendlhofer G et al (2000) Postprandial administration of the insulin analogue insulin aspart in patients with Type 1 diabetes mellitus. Diabet Med $17: 371-375$

11. Gerich JE (2004) Insulin glargine: long-acting basal insulin analog for improved metabolic control. Curr Med Res Opin 20:31-37

12. Garces K (2003) Insulin glargine: a long-acting insulin for diabetes mellitus. Issues Emerg Health Technol 52:1-4

13. Slieker LJ, Brooke GS, DiMarchi RD et al (1997) Modifications in the B10 and B26-30 regions of the B chain of human insulin alter affinity for the human IGF-I receptor more than for the insulin receptor. Diabetologia 40:S54-S61

14. Drejer K (1992) The bioactivity of insulin analogues from in vitro receptor binding to in vivo glucose uptake. Diabetes Metab Rev $8: 259-285$

15. Shymko RM, Dumont E, De Meyts P, Dumont JE (1999) Timingdependence of insulin-receptor mitogenic versus metabolic signalling: a plausible model based on coincidence of hormone and effector binding. Biochem J 339:675-683

16. Hansen BF, Danielsen GM, Drejer K et al (1996) Sustained signalling from the insulin receptor after stimulation with insulin analogues exhibiting increased mitogenic potency. Biochem J 315: 271-279

17. Soos MA, Whittaker J, Lammers R, Ullrich A, Siddle K (1990) Receptors for insulin and insulin-like growth factor-I can form hybrid dimers. Characterisation of hybrid receptors in transfected cells. Biochem J 270:383-390

18. Chisalita SI, Arnqvist HJ (2005) Expression and function of receptors for insulin-like growth factor-I and insulin in human coronary artery smooth muscle cells. Diabetologia 48:21552161

19. Bailyes EM, Nave BT, Soos MA, Orr SR, Hayward AC, Siddle K (1997) Insulin receptor/IGF-I receptor hybrids are widely distributed in mammalian tissues: quantification of individual receptor species by selective immunoprecipitation and immunoblotting. Biochem J 327:209-215

20. Nitert MD, Chisalita SI, Olsson K, Bornfeldt KE, Arnqvist HJ (2005) IGF-I/insulin hybrid receptors in human endothelial cells. Mol Cell Endocrinol 229:31-37

21. Kurtzhals P, Schaffer L, Sorensen A et al (2000) Correlations of receptor binding and metabolic and mitogenic potencies of insulin analogs designed for clinical use. Diabetes 49:9991005

22. Berti L, Kellerer M, Bossenmaier B, Seffer E, Seipke G, Haring HU (1998) The long acting human insulin analog HOE 901: characteristics of insulin signalling in comparison to Asp(B10) and regular insulin. Horm Metab Res 30:123-129

23. Staiger K, Staiger H, Schweitzer MA et al (2005) Insulin and its analogue glargine do not affect viability and proliferation of human coronary artery endothelial and smooth muscle cells. Diabetologia 48:1898-1905

24. Clowes AW, Schwartz SM (1985) Significance of quiescent smooth uscle migration in the injured rat carotid artery. Circ Res $56: 139-145$

25. Gockerman A, Prevette T, Jones JI, Clemmons DR (1995) Insulinlike growth factor (IGF)-binding proteins inhibit the smooth muscle cell migration responses to IGF-I and IGF-II. Endocrinology 136:4168-4173

26. Grant MB, Wargovich TJ, Ellis EA et al (1996) Expression of IGF1 , IGF-1 receptor and IGF binding proteins- $1,-2,-3,-4$ and -5 in human atherectomy specimens. Regul Pept 67:137-144

27. Goodyear LJ, Giorgino F, Sherman LA, Carey J, Smith RJ, Dohm GL (1995) Insulin receptor phosphorylation, insulin receptor substrate-1 phosphorylation, and phosphatidylinositol 3-kinase activity are decreased in intact skeletal muscle strips from obese subjects. J Clin Invest 95:2195-2204 
28. Del Valle L, Enam S, Lassak A et al (2002) Insulin-like growth factor I receptor activity in human medulloblastomas. Clin Cancer Res 8:1822-1830

29. Eckel J (2005) Insulin analogs revisited. Curr Med Chem Immunology, Endoc \& Metab Agents 5:475-484

30. Li G, Barrett EJ, Wang H, Chai W, Liu Z (2005) Insulin at physiological concentrations selectively activates insulin but not insulin-like growth factor I (IGF-I) or insulin/IGF-I hybrid receptors in endothelial cells. Endocrinology 146:4690-4696

31. Bornfeldt KE, Gidlof RA, Wasteson A, Lake M, Skottner A, Arnqvist HJ (1991) Binding and biological effects of insulin, insulin analogues and insulin-like growth factors in rat aortic smooth muscle cells. Comparison of maximal growth promoting activities. Diabetologia 34:307-313

32. Ciaraldi TP, Phillips SA, Carter L, Aroda V, Mudaliar S, Henry RR (2005) Effects of the rapid-acting insulin analog glulisine on cultured human skeletal muscle cells: comparisons with insulin and insulin-like growth factor I. J Clin Endocrinol Metab 90:5551-5558

33. Rakatzi I, Ramrath S, Ledwig D et al (2003) A novel insulin analog with unique properties: LysB3,GluB29 insulin induces prominent activation of insulin receptor substrate 2 , but marginal phosphorylation of insulin receptor substrate 1. Diabetes 52: 2227-2238 